\title{
2 PORTS AND 3 PORTS IN LAPAROSCOPIC APPENDECTOMY- A COMPARATIVE STUDY
}

\author{
Krishna Kishore $G^{1}$, Kiran Kumar K. $M^{2}$, Srinivas Arva ${ }^{3}$, Naveen H. $M^{4}$, Pratheek K. C ${ }^{5}$, Narendra M. $C^{6}$
}

${ }^{1}$ Senior Resident, Department of General Surgery, Sree Siddhartha Medical College, Tumkur.

${ }^{2}$ Professor, Department of General Surgery, Sree Siddhartha Medical College, Tumkur.

3 Professor, Department of General Surgery, Sree Siddhartha Medical College, Tumkur.

${ }^{4}$ Associate Professor, Department of General Surgery, Sree Siddhartha Medical College, Tumkur.

${ }_{5}^{5}$ Senior Resident, Department of General Surgery, Sree Siddhartha Medical College, Tumkur.

${ }^{6}$ Senior Resident, Department of General Surgery, Sree Siddhartha Medical College, Tumkur.

ABSTRACT
BACKGROUND
In conventional Laparoscopic Appendectomy, three ports are used wherein both the sub-umbilical and supra-pubic port sites are
hidden the by the natural camouflages and the only visible scar is the third port in the iliac fossa. The third port scar can be made
invisible by using a needle port for trans-parietal appendicular traction.

\section{MATERIALS AND METHODS}

This was a prospective study. This study consisted of 52 patients of Acute Appendicitis (AA) treated with Laparoscopic Appendectomy, 26 of whom were treated by Conventional Three Port Laparoscopic Appendectomy (CLA) and the remaining 26 cases treated by Modified Two Port Laparoscopic Appendectomy (TLA) in our hospital from October 2013 to March 2015 which included a minimum of six months of follow-up.

\section{RESULTS}

This Comparative study of 52 patients, with 26 patients undergoing CLA procedure and 26 patients undergoing TLA procedure for Acute Appendicitis. The mean operative time was 67.8 minutes CLA and 73.07 minutes TLA. The Duration of hospital stay was less in case of TLA group with a mean duration of 2.4 days in comparison with that of CLA group with mean duration of 3.5 days with significant statistical difference. There were no major complications in our study.

\section{CONCLUSION}

Two Port Laparoscopic Appendectomy is safe, cost-effective, cosmetically effective, and easy to learn and perform. Its aesthetic benefits are comparable to SILS and NOTES without requiring any special instruments. If intra-operatively found to be difficult, it can be converted into conventional laparoscopy by introducing a third port.

\section{KEYWORDS}

2 Ports, Modification of the Conventional Method.

HOW TO CITE THIS ARTICLE: Kishore KG, Kumar KKM, Arva S, et al. 2 ports and 3 ports in laparoscopic appendectomy- a comparative study. J. Evolution Med. Dent. Sci. 2017;6(8):633-638, DOI: 10.14260/Jemds/2017/136

\section{BACKGROUND \\ Acute Appendicitis (AA) is one of the most common surgical} emergencies encountered, for which there is an increasing trend towards Laparoscopic Appendicectomy (LA) which has many advantages compared to open method.1,2,3 No doubt Single Incision Laparoscopic Surgery (SILS) can be done with special multiport umbilical trocar and specialized instruments but has a steep learning curve due to loss of triangulation, clashing of instruments, lack of manoeuvrability, decreased technical expertise among the surgeons and an added financial burden to the patients, thus limiting its widespread use especially in rural/peripheral centres with limited resource.4,5 Recent development is natural orifice trans-luminal endoscopic surgery (NOTES).

Financial or Other, Competing Interest: None.

Submission 14-12-2016, Peer Review 14-01-2017,

Acceptance 20-01-2017, Published 25-01-2017.

Corresponding Author:

Dr. Krishna Kishore G

Flat No. 302,

Northeast Vaishnavi Residency,

Panchavati Colony,

Manikonda, Hyderabad, Telangana.

E-mail: krishnagorantla29@gmail.com

DOI: $10.14260 /$ jemds $/ 2017 / 136$
But, there are numerous difficulties including, complications of opening hollow viscera, failed sutures, lack of fully developed instrumentation and necessity of reliable cost-benefit analyses. ${ }^{6,7}$ In conventional three-port LA (CLA) from a cosmetic viewpoint, the umbilical and supra-pubic port sites are hidden by natural camouflages, but scar of the third port in the iliac fossa is the only visible external sign of surgery. Our modified technique avoids even this marker of abdominal invasion. In this technique, scars are invisible as the intra-abdominal entry points are hidden within the natural camouflages. This technique replicates the intra peritoneal view and operative technique of CLA, hence has a very short learning curve. Compared to SILS and NOTES, there is no need for expensive specialized equipment. TLA can be considered as the best procedure for selective cases of AA. 8

\section{MATERIALS AND METHODS}

All patients presenting to surgical OPD at SSMCH, Tumkur with clinical features of AA were confirmed by ultrasonography were included and laboratory investigations are done. Patients who are unfit for General anaesthesia, perforation with peritonitis, appendicular abscess and pregnancy were excluded. Informed consent from all the 
patients and ethical clearance from the committee were obtained. A detailed proforma was recorded.

\section{Procedure}

Patients were made to empty their bladder before lying on the operation table. Under General Anaesthesia, pneumoperitoneum of $12 \mathrm{~mm} \mathrm{Hg}$ was created. With $10 \mathrm{~mm}$ sub-umbilical camera port a diagnostic laparoscopy was done and another $5 \mathrm{~mm}$ supra-pubic working port introduced. Table positioned with head low and tilt to left side. This facilitates evaluation and mobilisation appendix with a grasper. Appendix was held in the grasper with traction towards the anterior abdominal wall. The tip of the grasper is felt by the surgeon externally, to know the point of best exposure of appendix in the right iliac fossa or even higher. An 18-gauge hypodermic needle traversed with a long prolene 1-0 suture material. This is Needle Loop Retractor (NLR) (fig. 1). NLR was punctured into the best suitable site (fig. 2) and it forms a loop in the abdomen to secure the appendix (fig. 3). If exposure is inadequate the NLR is replaced into a new site. The needle is slided backwards and the exteriorised prolene is clamped with an artery forceps on the abdominal wall (fig. 2) and the appendix is held taut. This produces trans-parietal appendicular traction (TAT) for the surgeon. If exposure is inadequate the position of transparietal suture can be changed by a suitable new puncture site. With bipolar diathermy mesoappendix is cauterized and the cut (fig 4). Roeder knot with polyglycocolic acid (Vicryl) 1-0 is made, introduced into the abdomen with Maryland forceps. Appendix released from the prolene loop, introduced into the Vicryl loop and again held taught by the polypropylene loop. Appendicular base ligated with Vicryl using a knot pusher (fig. 5). Similarly, one more Vicryl knot is applied to the appendix just distal to the first knot. Appendix is cut in between the knots and delivered out through umbilical port. The two laparoscopic port sites closed (fig. 6). Those cases which were difficult with NLR were converted to CLA by introducing the third $5 \mathrm{~mm}$ port in right iliac fossa port rescue. ${ }^{4}$ Total duration of the procedure was calculated from the time of incision up to the completion of skin closure. Pain in the post-operative period was rated using a Visual Analogue Scale (from 0 to 1). Procedure related complications during and after operations were recorded. Patients will be discharged from the hospital once they are fully mobilized and able to tolerate a normal diet.

\section{RESULTS}

This prospective study consisted of 55 patients with diagnosis of AA who were admitted in the surgical inpatient ward at SSMC Hospital, Tumkur and underwent LA during October 2013 to March 2015. They were divided into two groups i.e. CLA \& TLA which were operated by the surgeons in two surgical units dividing equal number in each group among them.

Of the 55 patients operated, 5 patients required conversion. Of which, 2 patients from 2 port group required addition of third port for adhesiolysis and 3 patients were converted from laparoscopy to Open appendectomy due to retrocaecal sub-hepatic appendix which was tightly hugging the caecum. Laparoscopic mobilisation of appendix was tried on these patients but with futile attempts thus requiring the open surgery, hence 3 patients were excluded from the study.
This Comparative study with 26 patients undergoing CLA procedure and 26 patients undergoing TLA procedure is undertaken to study the feasibility based on duration of operation, post-operative pain, intraoperative and postoperative complications. Descriptive statistical analysis has been carried out in the present study.

\section{Age}

In TLA group 5 Patients were in the age group of $0-20$ years, 10 patients were in the age group of $20-40$ years and 11 patients were in the age group of 40-60 years with a mean age of 36 years and a standard deviation of 14.7 years.

In CLA group, 7 Patients are in the age group of $0-20$ years, 15 patients are in the age group of 20-40 years and 4 patients are in the age group of 40-60 years with a mean age of 29.6 years and a standard deviation of 12.6 years.

The $\mathrm{P}$ value was insignificant.

\section{Gender Distribution}

In CLA group, there were 9 females and 17 males while in TLA group there were 8 females and 18 males with a P value of 0.76 which is insignificant.

\section{Duration of Surgery}

The mean operative time was 67.8 minutes for CLA and 73.07 minutes for TLA $p$ with a $P$ value of 0.01 . The overall mean operative time was significantly less in CLA in comparison with TLA.

\section{Post-Operative Pain}

Pain score in CLA group, 9 Patients (35 \%) with a score of $<3$ (mild pain), 12 Patients (46\%) with a score of 3-6 (discomforting) and 5 Patients (19\%) with a score of $>6$ (distressing).

Pain score in TLA group, 16 Patients (61.5\%) with a score of $<3$ (mild pain), 8 Patients (30.7\%) with a score of 36(discomforting) and 2 Patients (7.6\%) with a score of $>6$ (distressing).

Patients in TLA group had less pain than those in CLA group.

The comparative $\mathrm{P}$ value is 0.13 which was statistically insignificant.

\section{Postoperative Complications}

Surgical site infection was present in a total of 7 cases out of 52 with 5 from CLA group and 2 cases from TLA group.

\section{Period of Hospitalisation}

Period of Hospitalization for patients in CLA group, 9 Patients (35\%) had a hospital stay of 0-2 days, 12 Patients (46\%) a hospital stay of 2-4 days and 5 Patients (19\%) a hospital stay of 4-6 days. In TLA group, 16 Patients (61.5\%) had a hospital stay of $0-2$ days, 8 Patients (30.7\%) had a hospital stay of $2-4$ days and 2 Patients (7.6\%) had a hospital stay of 4-6 days. A P value of $<0.0001$ was observed which is statistically very significant.

Hence, Patients who underwent TLA had a significantly less hospital stay in comparison with those who underwent CLA. 


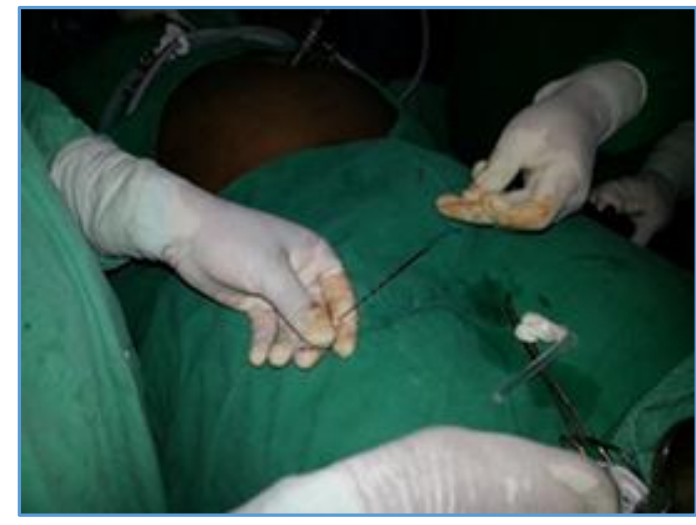

Figure 1. Polypropylene suture material passed through 18 gauge needle to prepare a NLR

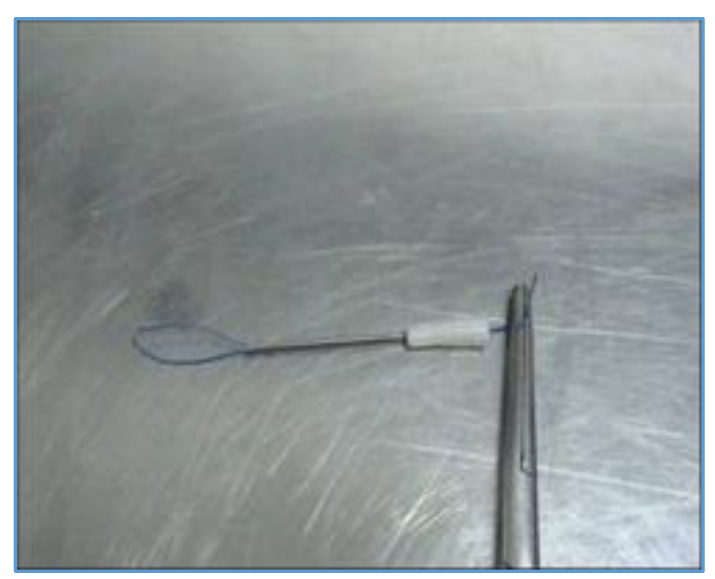

Figure 2. Needle Loop Retractor

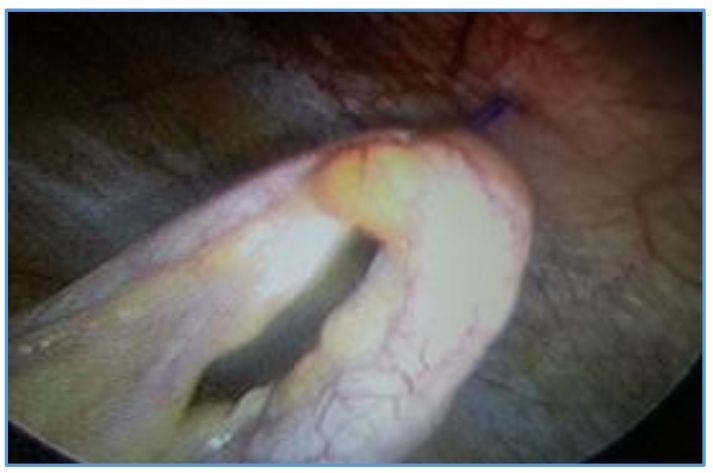

Figure 3. Appendix is held within the loop of NLR against the anterior abdominal wall

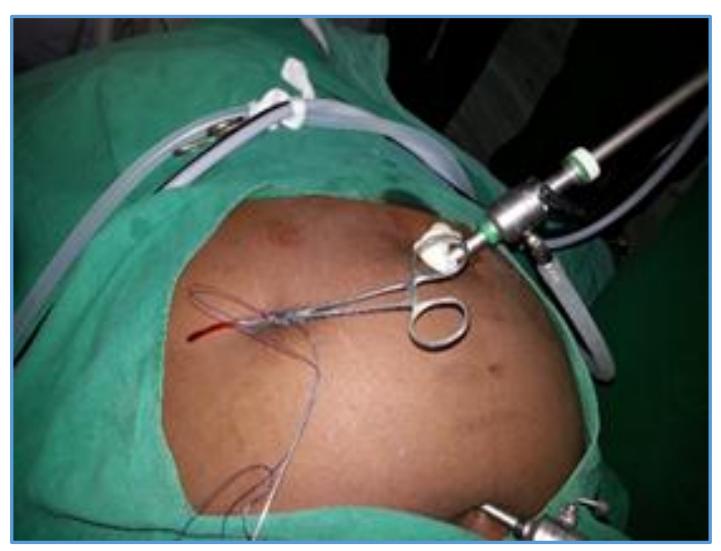

Figure 4. NLR is fixed extra-corporeally using Puppeteer technique

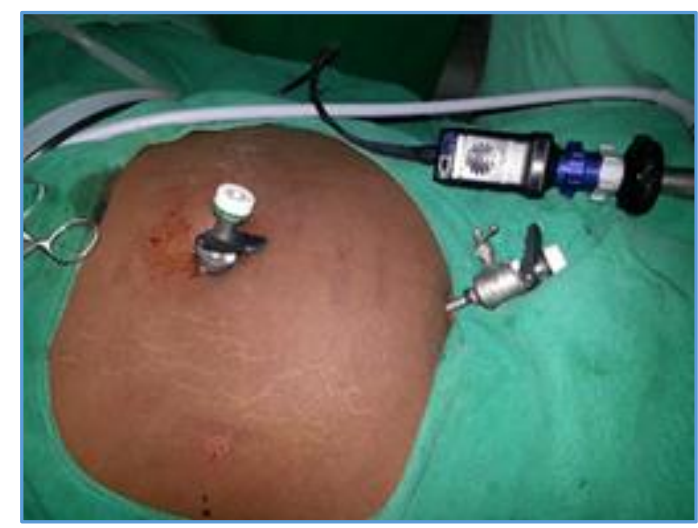

Figure 5. 2 port sites in TLA

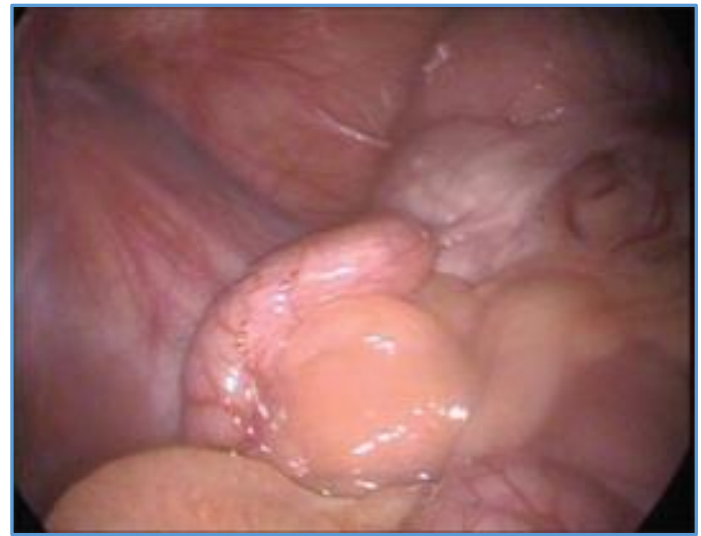

Figure 6. Intraperitoneal View of Inflamed Appendix

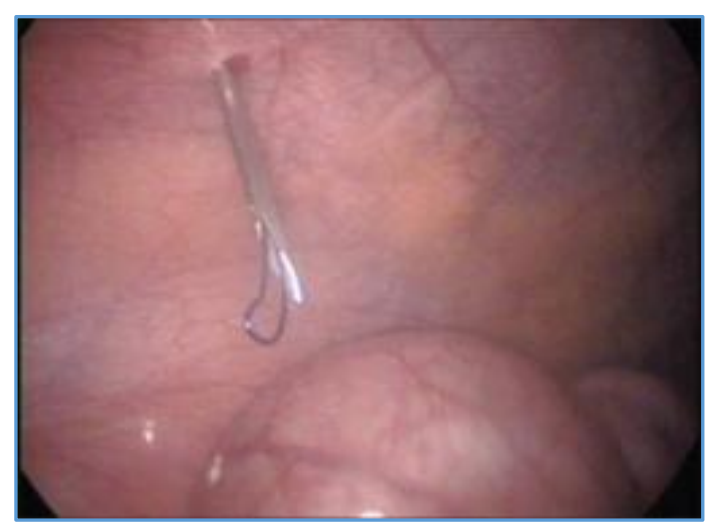

Figure 7. Intraperitoneal view of the insertion of needle loop retractor

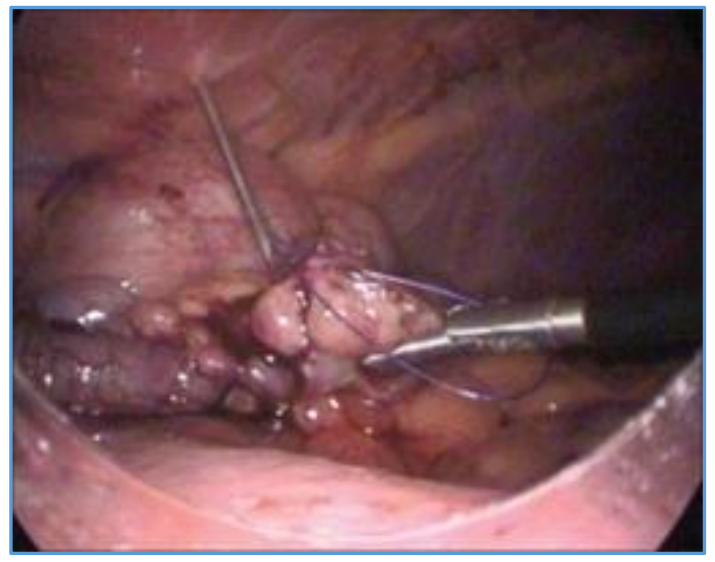

Figure 8. Snaring of Appendix using NLR 


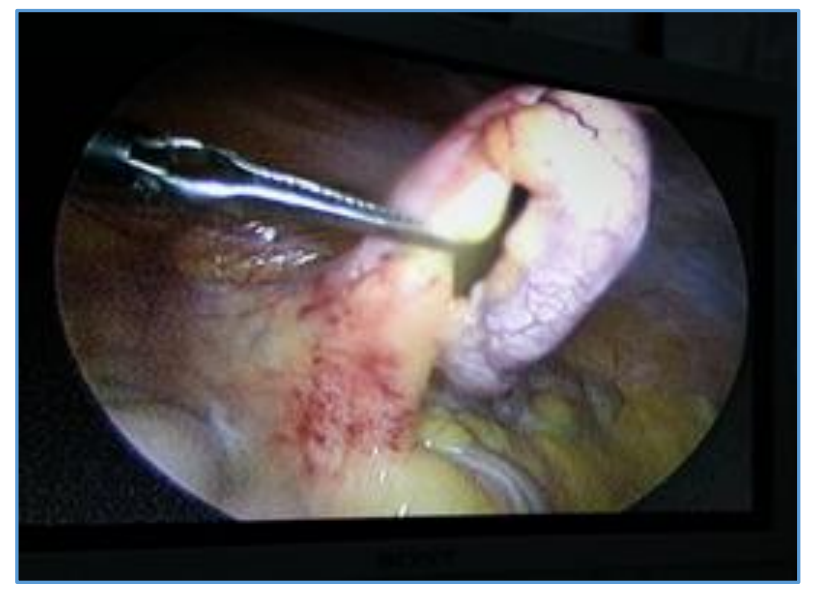

Figure 9. Mesoappendix transected using bipolar diathermy

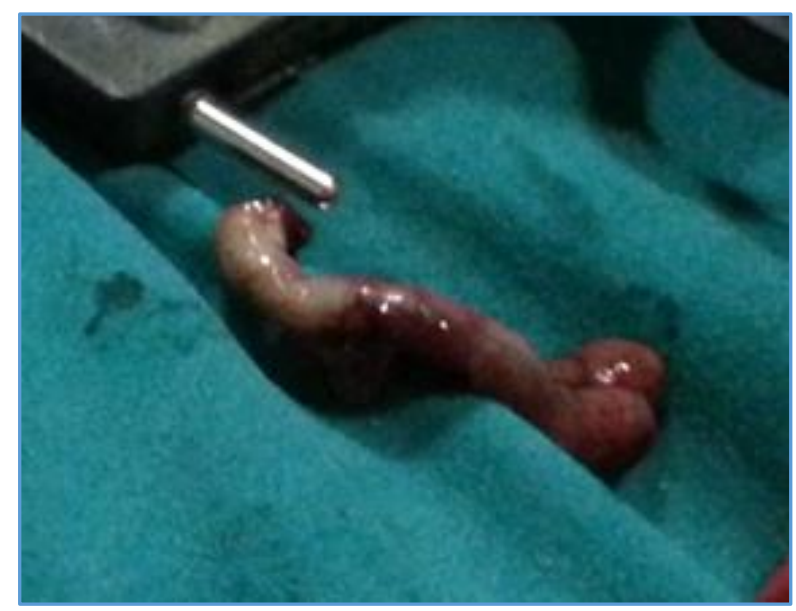

Figure 10. Excised Appendix

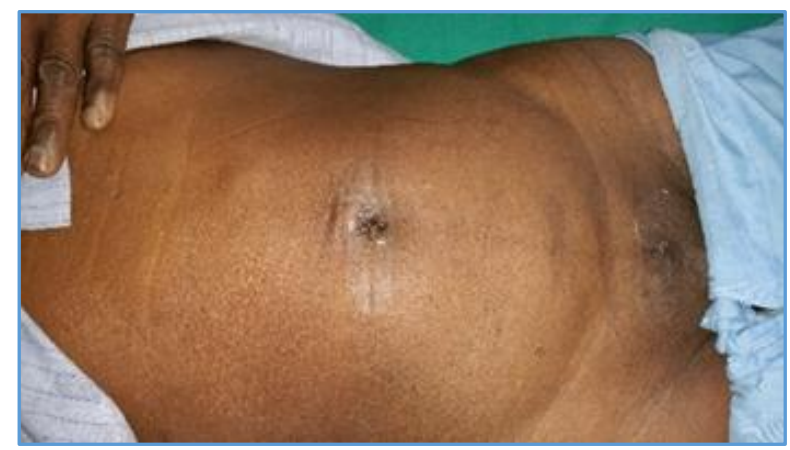

Figure 11. Postoperative day 2 of wound of TLA

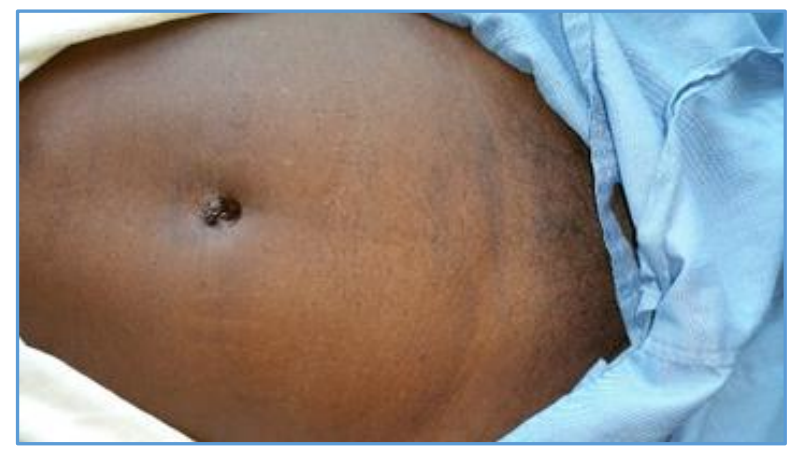

Figure 12. Wound status after suture removal suggestive of no scar in RIF/LIF

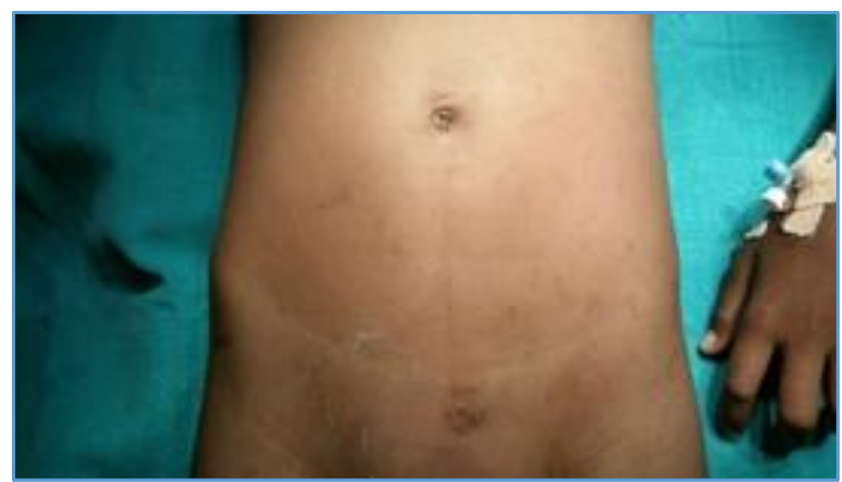

Figure 13. Wound status following TLA after 6 months follow up suggestive of virtual scarless surgery.

\section{DISCUSSION}

This was also done to identify the subset of patients who would benefit more, from a particular type of Laparoscopic Appendectomy.

\section{Age \& Gender}

Our study did not have a age limit so we had operated on patients in different age groups.

It was easier to perform Laparoscopic appendectomy in adults in comparison with those of patients below 15 years due the working space in adults is more compared to children. Among a total of 52 patients, 37 were Males and 17 were Females.

The procedure of TLA was cosmetically more acceptable by both males and females in comparison with CLA due to the absence of scar of the other port. Female patients were particularly happier about the absence of the third visible scar on the abdomen compared to males.

\section{Duration of Surgery}

The overall mean operative time was significantly less in CLA procedure in comparison with TLA procedure. This is one important drawback of TLA procedure. The manoeuvrability with single instrument is difficult and sometimes it is more tedious in case of hidden appendicitis, due to retrocaecal position and adhesions.

The Mean duration of surgery was 73.07 min for TLA which took little longer in comparison with other studies like, Paniat L et $\mathrm{al}^{9}$ reported a mean duration of TLA procedure of 64.1 min. Ashwin Rammohan et al ${ }^{10}$ reported the mean operative time for surgery of $55.7 \mathrm{~min}$ and in a similar study conducted by Jose Gustavo Olijnyk et al the mean operative time for TLA was $64.5 \mathrm{~min}^{11}$ respectively.

The procedure of TLA had initially taken some time to learn but once learnt, it was easier to perform and this procedure also had taken more time in case of a short appendix and in cases on adhesions.

\section{Post-Operative Pain}

The difference between the two groups was not statistically significant with a $\mathrm{p}$ value of 0.13 .

The patients in TLA group had better tolerated the procedure due to less postoperative pain in comparison with those in CLA group due to the absence of the additional port.

\section{Postoperative Complications}

There were no major complications in either groups, but we 
had 7 patients with minor complications of surgical site infection in our study. 5 patients in CLA group (19.2\%) \& 2 patients (7.6\%) in TLA group had minor complications.

A P value 0.22 was observed and is considered statistically insignificant.

Ashwin Rammohan 10 et al had reported a postoperative complication rate of $3.9 \%$ in TLA in comparison with CLA which was $4.8 \%$ which was insignificant.

This shows that there are no typical postoperative complications in particular to TLA procedure.

\section{Period of Hospitalization}

In our study, Mean POH in TLA group was 2.4 days and For CLA group was 3.5 days. A P value of $<0.0001$ was observed which is statistically very significant.

Hence, Patients who underwent TLA had a significantly less hospital stay in comparison with those who underwent CLA.

This coincides with the study done by Fazili FM et al ${ }^{12}$ with $(\mathrm{n}=129)$.

Shorter stay in TLA might be due to lesser postoperative pain to the patients. ${ }^{9}$

In a study conducted by Ashwin Rammohan et al ${ }^{10}$ the mean length of hospital stay was 2.1 days for TLA while it was 4.2 days in CLA.

When compared to POH of our study with mean length of stay for TLA was 2.4 days and for CLA was 3.5 days similar results of $\mathrm{POH}$ was observed in Fazili et al. and Ashwin Rammohan et al.

TLA is more cost effective to the patient due to lesser duration of hospital stay and lesser pain since it requires only 2 ports thus would have an added advantage of not requiring an assistant which further decreases the cost of the procedure. The patient can resume his routine activities much earlier.

In CLA, the use of 5-10 mm ports in the umbilical and RIF, right hypochondrial or left iliac fossa regions often leave clearly visible scars. We have demonstrated that TLA using a needle loop retractor (NLR) to replace the RIF trocar and the suprapubic trocar strategically placed below the hairline to be a safe and feasible procedure. It also has other advantages, even when inflammation is extensive, the ability to hold both the appendix and the mesoappendix at the same time with a loop retractor enables more stable manipulation and counter traction than the use of conventional forceps and this procedure is also associated with less risk of causing an uncontrolled tear in the mesoappendix or an iatrogenic perforation of the appendix. Even though we have described the site of NLR as RIF, flexibility in its placement is vital and best decided following an intraoperative view of the pathology. The NLR can easily be sited elsewhere in the abdomen so as to ergonomically and cosmetically suit the pathology and the surgeon. If necessary, a surgeon can easily convert a two-port procedure to a conventional three-port procedure by adding another trocar. This allows the safety of the patient to be preserved. Our technique also eliminates one site of peritoneal invasion thereby reducing the chances of adhesions.

Kollmar et al described moving laparoscopic incisions to hide them in the natural camouflages like the suprapubic hairline and improve cosmesis. ${ }^{13}$ Additionally, reports in the literature indicate that mini-laparoscopic appendectomies using 2-3 mm or even smaller instruments along with one 12- mm port minimizes pain and improve cosmesis. ${ }^{14,15,16}$ More recently, studies by Ates et al. and Roberts et al. have described variants of an intracorporeal sling based singleport laparoscopic appendectomy with good clinical results. 17,18

\section{CONCLUSION}

Two Port Laparoscopic Appendectomy is safe, cost-effective, cosmetically effective, and easy to learn and perform. Its aesthetic benefits are comparable to SILS and NOTES without requiring any special instruments. If intra-operatively found to be difficult, it can be converted into conventional laparoscopy by introducing a third port.

\section{REFERENCES}

[1] Eypasch E, Sauerland S, Lefering R, et al. Laparoscopic versus open appendectomy: between evidence and common sense. Dig Surg 2002;19(6):518-22.

[2] Yagnik VD, Rathod JB, Phatak AG. A retrospective study of two-port appendectomy and its comparison with open appendectomy and three-port appendectomy. Saudi J Gastroenterol 2010;16(4):26871.

[3] Garbutt JM, Soper NJ, Shannon WD, et al. Meta-analysis of randomized controlled trials comparing laparoscopic and open appendectomy. Surg Laparosc Endosc 1999;9(1):17-26.

[4] Udwadia TE. Single-incision laparoscopic surgery: an overview. J Minim Access Surg 2011;7(1):1-2.

[5] Rao PP, Rao PP, Bhagwat S. Single-incision laparoscopic surgery - current status and controversies. J Minim Access Surg 2011;7(1):6-16.

[6] Chamberlain RS, Sakpal SV. A comprehensive review of Single-Incision Laparoscopic Surgery (SILS) and Natural Orifice Transluminal Endoscopic Surgery (NOTES) technique for cholecystectomy. J Gastrointest Surg 2009;13(9):1733-40.

[7] Romanelli JR, Earle DB. Single-port laparoscopic surgery: an overview. Surg Endosc 2009;23(7):141927.

[8] Husain M, Sahu S, Sachan P. Two-Port Laparoscopic appendectomy. The Internet Journal of Surgery 2010:27(2).

[9] Panait L, Bell RL, Duffy AJ, et al. Two-port laparoscopic appendectomy: minimizing the minimally invasive approach. J Surg Res 2009;153(1):167-71.

[10] Rammohan A, Jothishankar P, Manimaran AB, et al. Two-port vs. three-port laparoscopic appendicectomy: a bridge to least invasive surgery. J Min Access Surg 2012;8(4):140-4.

[11] Olijnyk JG, Pretto GG, Omero da Costa FOP, et al. Twoport laparoscopic appendicectomy as transition to laparoendoscopic single site surgery. JMAS 2014;10(1):23-6.

[12] Fazili FM, Al-Bouq Y, El-Hassan OM, et al. Laparoscope-assisted appendectomy in adults: the two trocar technique. Ann Saudi Med 2006;26(2):100104.

[13] Kollmar O, Z'graggen K, Schilling MK, et al. The suprapubic approach for laparoscopic appendectomy. Surg Endosc 2002;16(3):504-8. 
[14] Gotz F, Pier A, Bacher C. Modified laparoscopic appendectomy in surgery. A report on 388 operations. Surg Endosc 1990;4(1):6-9.

[15] Matthews BD, Mostafa G, Harold KL, et al. Minilaparoscopic appendectomy. Surg Laparosc Endosc Percutan Tech 2001;11(6):351-5.

[16] Schier F. Laparoscopic appendectomy with 1.7-mm instruments. Pediatr Surg Int 1998;14(1-2):142-3.
[17] Ates O, Hakguder G, Olguner M, et al. Single-port laparoscopic appendectomy conducted intracorporeally with the aid of a transabdominal sling suture. Journal of Pediatric Surgery 2007;42(6):10714.

[18] Roberts KE. True single-port appendectomy: first experience with the puppeteer technique. Surg Endosc 2009;23(8):1825-30. 